\section{Minority ethnic men in British labour market (1972-2005)}

Minority ethnic men

\author{
Yaojun Li
}

Department of Sociology, Birmingham University, Birmingham, UK, and Anthony Heath

Department of Sociology, Oxford University, Oxford, UK

\begin{abstract}
Purpose - This paper seeks to investigate ethnic disadvantages in the UK labour market in the last three decades.

Design/methodology/approach - Drawing on data from the most authoritative government surveys, the gross and net differences in employment status and class position between minority ethnic and White British men covering 34 years (1972-2005) are analysed.

Findings - White British and White Other men were generally advantaged in employment and in access to professional and managerial (salariat) jobs. White Irish men were making steady progress, and have now caught up with the White British. Black men were much more likely to be unemployed in recession years but progress is discernible with Black Caribbeans approaching, and Black Africans frequently outperforming, the White British in gaining access to the salariat. Indian and Chinese men were behind the White British in employment but little different in access to the salariat. Pakistani/ Bangladeshi men were most disadvantaged in both respects.

Originality/value - This is the most systematic research in this area so far, using the most authoritative data and covering such a long period.
\end{abstract}

Keywords Employment, Social status, Human capital, Ethnic groups

Paper type Research paper

\section{Introduction}

In this paper we conduct a systematic analysis of the labour market trajectories of men in different ethnic groups in Britain over the last three decades (1972-2005) using the most authoritative government datasets from the General Household Survey (GHS) and the Labour Force Survey (LFS)[1]. The analysis focuses on patterns and trends on employment status and class position. We pay particular attention to the role of education on employment and occupational attainment. The overall aim is to show how the different ethnic groups were faring in the British labour market in the last three decades and, in so doing, to place the debate on ethnic socio-economic integration on a firmer empirical basis.

\section{Theoretical context}

Britain is becoming increasingly multi-ethnic, with the proportion of minority ethnic groups growing from 2.1 per cent in 1951 to 8.0 per cent in 2001. The presence and the continued growth of the minority ethnic population have attracted serious attention from academia and government organisations. This is because the socio-economic position of the minority ethnic groups affects not only their own well-being, but the future status of the country as a major player in an ever-increasing globalised world. Furthermore, as the White British population has an ageing structure, improving the socio-economic conditions of the minority ethnic groups through employment and upward social mobility is not only an issue of social justice and civic liberty, it is concerned with the future economic prosperity of all members in the society.

Studies of racial discrimination abound, dating back nearly 40 years (Daniel, 1968). Yet research on ethnic disadvantages using quantitative data did not come until the
Received 29 April 2007 Revised 30 June 2007 Accepted 7 July 2007 
IJSSP

28,5/6

232 1990s. The release of the 1991 census, particularly the samples of anonymised records (SARs) from the census, prompted a huge research programme on ethnic relations by academic and government researchers. Nearly 400 papers and monographs using the SARs were published by leading social scientists (Karn, 1997; Li, 2004). Since then, ethnic data have been available in all large-scale government and academic surveys, and research using more recent data has continued unabated (Heath and Yu, 2003; Brook, 2005; Li, 2005). Yet little systematic research has been conducted on the patterns and trends of the economic fortunes of the minority ethnic groups covering the period during which the great majority of ethnic minority groups came to settle in the country.

There are ongoing debates on the nature and the extent of ethnic discrimination and disadvantage. Existing research using the 1991 census and more recent data shows considerable differences both between the minority ethnic groups and the Whites, and among the minority ethnic groups themselves, in a whole range of areas such as education, employment, occupation, housing, health and social deprivation (Drew et al., 1997; Li, 2006a). The most serious disadvantages are faced by Black-Caribbeans, Black Africans, Pakistanis and Bangladeshis. Even members of minority ethnic groups that are generally perceived as "doing well" are found to fall behind Whites in socioeconomic attainment when personal attributes and educational qualifications are taken into account (Carmichael and Woods, 2000). On the other hand, there are signs of growing social integration by certain ethnic groups as shown in the increasing rates of intermarriage, especially between some Black groups and Whites (Dale et al., 2000).

We focus on the role of education on labour market attainment. Here we find some powerful theoretical grounds for believing that the minority ethnic groups will have more favourable outcomes in the labour market as the time goes on. First of all, new immigrants will often lack the kinds and levels of skills (human capital) that are relevant in the country of destination. Labour migrants in particular will often have relatively low levels of education and other forms of human capital and, on this account alone, would be expected to fill low-level jobs or to be engaged in small businesses. Minority ethnic groups are sometimes forced to be in self-employment as an "escape strategy" when confronted with covert or overt discrimination in the mainstream labour market (Clark and Drinkwater, 1998). This is particularly so as reflected in the "hyper-cyclical" nature of unemployment, that is, at times of economic recession, the unemployment rates of minority ethnic groups are disproportionately high. Secondly, immigrants will tend to experience what might be called an "immigration penalty": the qualifications that they obtained at home are often regarded by employers as having less relevance or value on the British labour market; their experience in the home labour market are not easily transferable to the British labour market; they may lack fluency in English; and their social networks may have been disrupted by the very act of migration. Third, migrants, perhaps especially those from culturally dissimilar backgrounds, or those that are particularly "visible", may experience discrimination either in the labour market directly, or in housing or other areas of life that may impact indirectly on their labour market opportunities (Heath and Li, 2007).

As time goes on, many of the disadvantages faced by earlier cohorts of minority ethnic groups are expected to be gradually reduced: the anti-discrimination acts may begin to take effect and in addition, following the "contact" hypothesis (Hamberger and Hewstone, 1997) prejudice against ethnic minorities may decline as the majority population have had more contact with minorities. The minority groups themselves will have a better command of the English language and more experience of the British labour market as an increasing proportion of them will be second or third generation 
who, born and educated in Britain, can be expected to have similar human and social capital to that possessed by their White counterparts. The central concern of this paper, therefore, is to see whether this optimistic hypothesis of narrowing gaps over time between majority and minority populations is confirmed by rigorous investigation.

\section{Data and analysis}

In order to conduct the study, a large number of data sets are used from the GHS (19722005) and the LFS (1983-2005). They are government surveys well known to the academic users. The GHS is an annual survey (with the exception of 1997/1998 and 1999/2000), as is the LFS from 1983 to 1991[2]. From 1992 onwards, the LFS became a quarterly panel survey with a rotating structure. The annual data from 1983 to 1991 and Wave 1 data of each season in each year from 1992 onwards are selected and pooled with the GHS, as Wave 1 data have face-to-face interviews with a much higher response rate than that in Waves 2-5. The pooled data has nearly five million records with around 47 thousand cases for minority ethnic groups: the largest and most authoritative dataset ever assembled for this kind of research. In this paper, we confine the analysis to men aged 16-64 and resident in Great Britain at the time of interview, with a sample size of over 1.5 million records. In the following, we shall first look at the overall patterns and trends in employment status and class, and then investigate the net effects (or ethnic penalties) after controlling for measures of human capital.

The data in Figure 1 shows the patterns and trends of employment status in the 34 years covered. As discussed earlier, a great deal of research has been conducted on the employment situation of ethnic groups, but most of the research focused on one or two time points and only a few analyses covered a longer time period (Heath and Cheung, 2007; Iganski and Payne, 1999; Berthoud and Blekesaune, 2006). Here we provide the first evidence based on the most authoritative data covering 34 years. The figure has three panels: employed, unemployed and economically inactive. In each panel, we provide information on eight main groups in each year[3]. The eight groups are: White British, White Irish, White Other, Black Caribbean, Black African, Indian, Pakistani and Bangladeshi (combined due to sample sizes), and Chinese. Researchers sometimes include an "Other" category comprising White and Black mixed, White and Asian mixed and other sundry groups. In order not to make the graph too congested, we do not show the data on the Other group here but will discuss them in the modelling part.

Panel 1 in Figure 1 shows the proportions in employment. It is clear that throughout the period, it is the White British and White Other men who had the highest rates of employment: around 90 per cent in employment up to 1980 and around 80 per cent thereafter. The employment situation was generally good in the 1970s with some, but not much, ethnic difference. After that time, the ethnic differences became much bigger and remained fairly constant. In much of the mid 1980s and in the early 1990s, the differences became very large indeed, especially for men of Black African and Pakistani/Bangladeshi heritage. In many of those years, the differences ran as much as some 30 percentage points. It is also noted that the differences between White Irish and Indian men on the one hand and the White British men on the other were, albeit noticeable, not very big, at around 7-10 percentage points. The line for the Black Caribbean men was somewhere in the middle. It is also noted that the employment rates of the Chinese men were drifting towards the low, which is confirmed by other

\section{Minority ethnic}

men

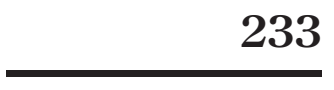


IJSSP

$28,5 / 6$

\section{4}

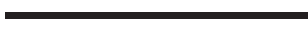

Figure 1.

Employment status of men aged 16-64 in Britain
Panel 1: Probability of being employed

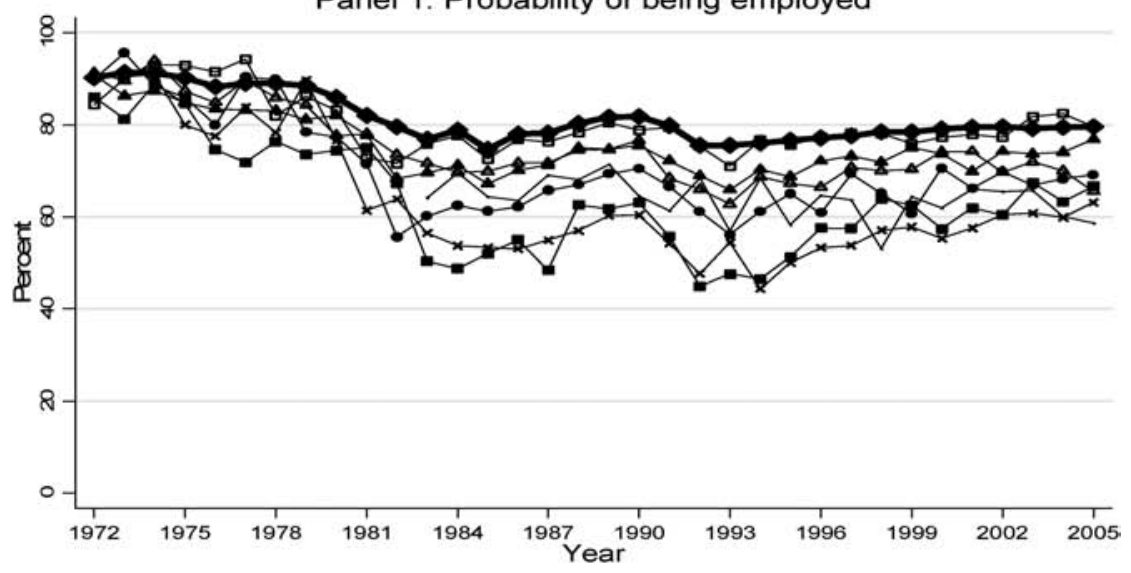

Panel 2: Probablity of being unemployed

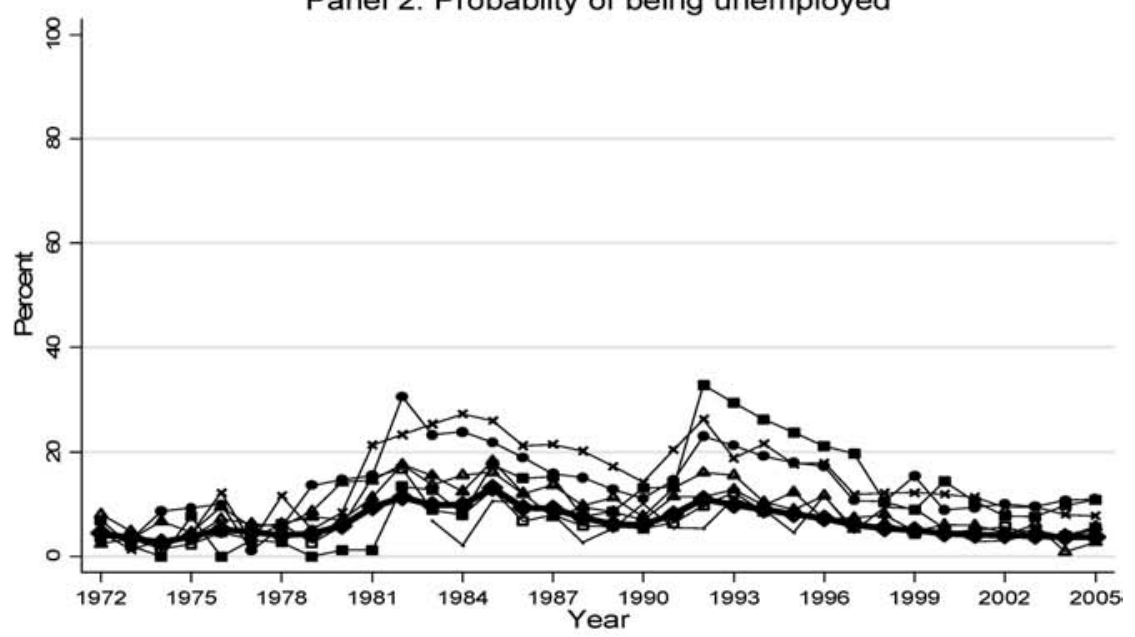

Panel 3: Probablity of being inactive

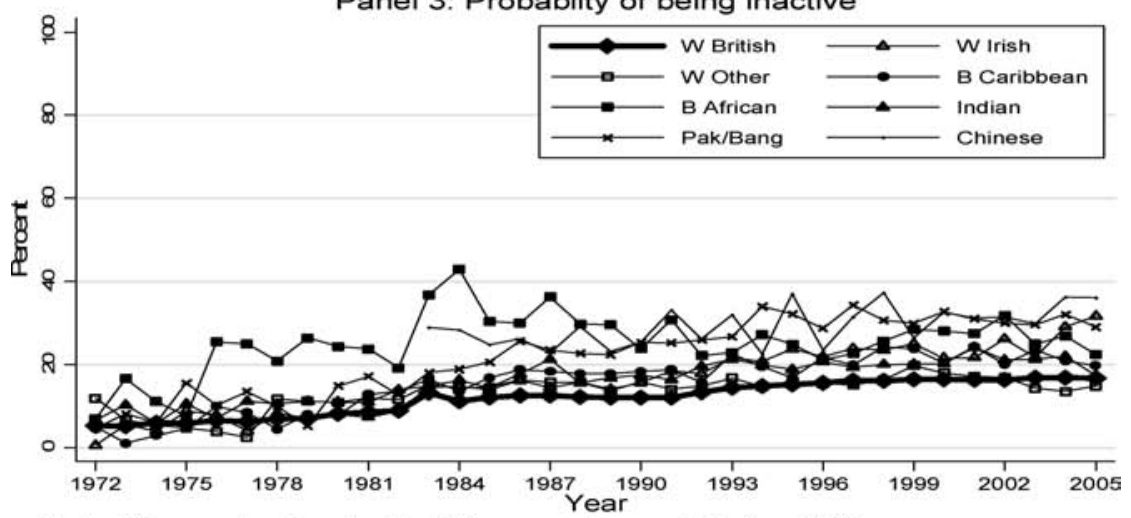

Note: The sample sizes for the Chinese are too small before 1983 .

Source: Pooled data of GHS/LFS (1972-2005). 
data sources[4]. Although the reason awaits further exploration, it may well be a consequence of increasing Chinese participation in higher education (Li, 2006b).

The patterns on employment are, of course, closely related to those of unemployment and inactivity. Looking at the patterns and trends in the two lower panels of Figure 1, we find two main features. First, from around 1980 when the general economic situation became more unfavourable, the White groups were weakly, and Black Caribbean and Pakistani-Bangladeshi men strongly, affected in terms of having both higher unemployment and higher inactivity rates. In the second peak of economic recession in the early 1990s, it was again these two groups plus the Black African men who were disproportionately unemployed and inactive. Given that our samples were limited to men of working age, many of those in inactivity could well be "discouraged workers", that is, those who believed that there were "no suitable jobs for me" and who came to terms with life by taking earlier retirement or being on "disability" benefits. In the sociological sense, much of the economic inactivity of the men in question, especially men from the more disadvantaged ethnic groups, could well be regarded as hidden unemployment.

As the economic situation improved in the last few years of our period, both the ethnic minority unemployment and inactivity rates moved back closer to the figures for the majority population, confirming the idea that ethnic minority worklessness is hypercyclical.

The data in Figure 2 concern class positions. Here we differentiate three main classes: the salariat - professionals and managers; the intermediate class - office clerks, small employers, manual supervisors, and lower technicians; and the working class - skilled, semi-skilled and unskilled manual workers including agricultural labourers. The patterns and trends of class occupancy by men in each of the ethnic groups are shown in the three panels, respectively.

With regard to access to the salariat (Panel 1), the most striking feature that manifests itself is the continued expansion of "room at the top". Take the White British men for example. In 1972, around 20 per cent were found in this class. In 2005, the proportion doubled. Yet, the good fortune was not equally shared. The rates for men of Pakistani/Bangladeshi heritage fluctuated before the 1990s and remained at around 20 per cent after that.

Some other features are also noteworthy. First, the White British men were never the most likely to gain access to the salariat throughout the period covered. The White Other men were in fact the most likely to gain access to this class. Men of Black African origins were constantly outperforming the White British in this regard, even though, as we have seen, they were much more likely to be out of employment in the recession years. In this sense, the Black African group has the greatest within-group social stratification. The White Irish men were consistently lagging behind their White British counterpart in gaining access to this class up to the early 1990s but since then had been catching up and were surpassing the latter in the last few years of the period covered. Men of Indian and Chinese heritage were not much different from the White British in the entire period covered. The fortunes of Black Caribbean men were consistently improving. In the earlier period, they had a gap of around 10 percentage points behind the White British men in terms of gaining access to the salariat and, in the last ten years covered, the gap narrowed to around five points.

With regard to incumbency in the intermediate class, we find that men of Chinese, Pakistani/Bangladeshi and Indian heritage were consistently more, and the two Black groups were less, likely to be in this class than their White British peers. Further
Minority ethnic men

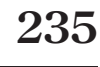


IJSSP

28,5/6

236
Figure 2.

Class position of men aged 16-64 in Britain
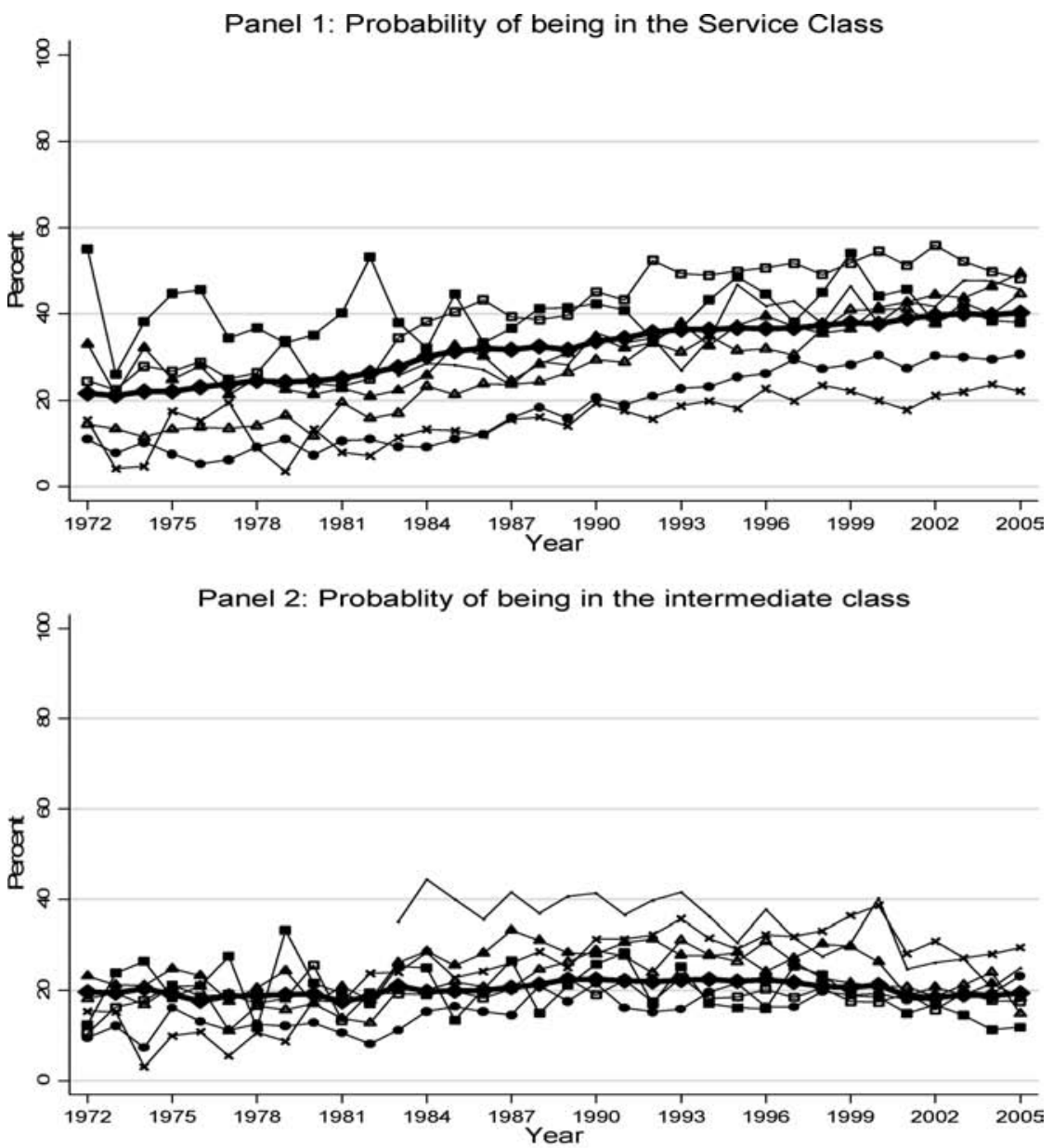

Panel 3: Probablity of being in the working class

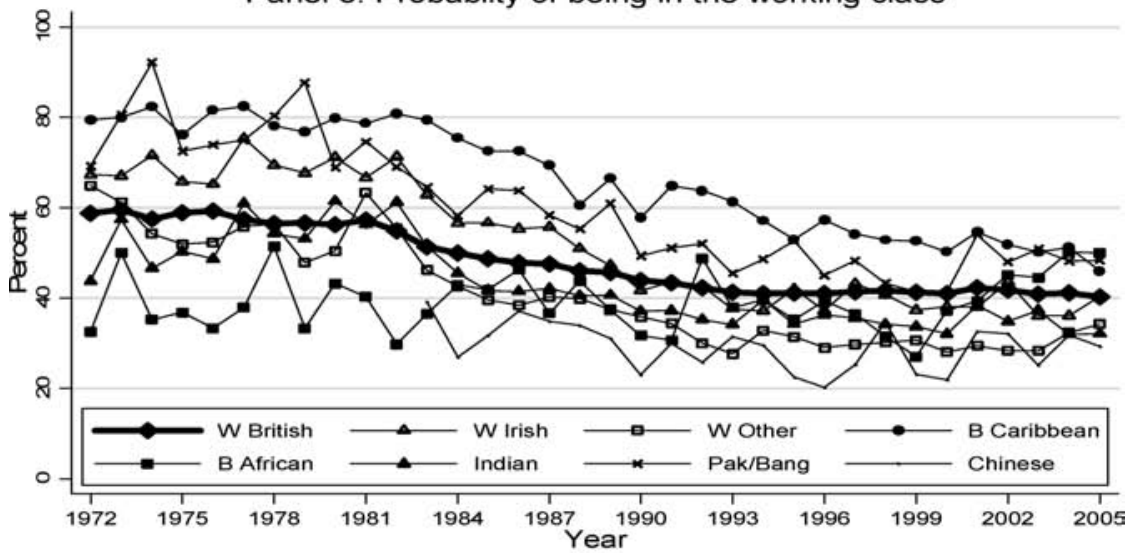

Note: The sample sizes for the Chinese are too small before 1983 .

Source: Pooled data of GHS/LFS (1972-2005). 
analysis (data not presented here but available on request) shows that the differences pertain mainly to self-employment. One cannot, in this regard, simply equate selfemployment to advantage or disadvantage. For instance, the Chinese are most likely to be in self-employment but most of them are sole-traders, family businesses or small employers. By contrast, Black Africans are much less likely to be self-employed but for those amongst them who do become entrepreneurs, they are much more likely to be big employers than any other groups (Li, 2006b).

The patterns and trends on working-class occupancy (Panel 3) show substantial differences between ethnic groups. Throughout the period covered, the line for the White British men is in the middle, with lines for Black Caribbean and Pakistani/ Bangladeshi and, in the earlier period, White Irish men above it. Men of White Other, Indian, Chinese and, in the earlier period, Black African origins were less likely to be in the manual working class.

The above is concerned with what might be called the "gross" or "raw" differences in labour market positions. We know that the different minority ethnic groups came to Britain at different time points, with nearly half (48.4 per cent) of Black Caribbean men born in Britain, as against only 17 per cent for the Chinese; that their educational qualifications varied enormously, with 24 per cent of Black African men as compared with only 6 per cent of Black Caribbean or 10 per cent of Pakistani/Bangladeshi men having a degree; and that their family circumstances also differed a great deal, with Pakistani/Bangladeshi men being two and a half times as likely to have dependent children as the White groups. All this may have an impact on employment and occupational attainment. It is thus important to take account of these factors in order to assess the "net" or relative differences between ethnic groups.

In the following part of this section, we address the issue of relative effects in gaining access to employment and avoidance of unemployment, and in gaining access to the salariat and avoidance of other classes, controlling for personal attributes and human capital indicators. We also carried out an analysis comparing employment vs unemployment plus inactivity (that is, vs non-employment). The patterns are similar (data not presented but available on request) but since in this age group inactivity contains students, early retired, disabled, "discouraged workers", etc., we believe it conceptually more useful to compare employment with unemployment.

The data are in Tables I and II where we present logistic regression coefficients. We code employment $=1$ and unemployment $=0$, and salariat $=1$ and other classes $=0$, for analysis in the two tables, respectively. In both tables, we conduct four models. In Model 1, we use only the ethnic groups (and we include the "Other" group here as noted above). In Model 2, we add personal attributes such as marital status, number of dependent children in household, and period effects where we differentiate earlier (1972-1980), middle (1981-1996) and later (1997-2005) periods. In Model 3, we add human capital indicators such as age and education for experience and skills, and country of birth for nativity effects, hence first or second generation. Finally, in Model 4, we add interaction effects for each of the main minority ethnic groups and the middle/later periods. This way, we cannot only see the effects of personal and human capital variables, we can further see the changes in the coefficients associated with the ethnic groups as we include more variables in the models. Moreover, we can discern whether and to what extent any of the ethnic groups were making progress and catching up with the majority population as time went on from the earlier to the later periods.

\section{Minority ethnic} men

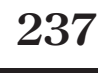


IJSSP

28,5/6

238

Table I.

Logit regression coefficients on employment

\begin{tabular}{|c|c|c|c|c|}
\hline & Model 1 & Model 2 & Model 3 & Model 4 \\
\hline \multicolumn{5}{|l|}{ Ethnicity } \\
\hline White British (ref) & 0 & 0 & 0 & 0 \\
\hline White Irish & $-0.383^{* * *}$ & $-0.392^{* * * *}$ & $-0.408 * * *$ & $-0.489 * * *$ \\
\hline White Other & 0.014 & -0.005 & -0.035 & -0.019 \\
\hline Black Caribbean & $-0.988^{* * * *}$ & $-0.945^{* * *}$ & $-0.857 * * *$ & $-0.492^{* * *}$ \\
\hline Black African & $-0.959 * * *$ & $-1.052^{* * * *}$ & $-1.174 * * *$ & 0.433 \\
\hline Indian & $-0.298 * * *$ & $-0.333^{* * * *}$ & $-0.334 * * *$ & $-0.325^{* * *}$ \\
\hline Pakistani/Bangladeshi & $-1.109 * * *$ & $-1.187 * * *$ & $-0.904 * * *$ & -0.079 \\
\hline Chinese & -0.079 & -0.110 & -0.132 & -0.036 \\
\hline Other & $-0.589^{* * * *}$ & $-0.679 * * *$ & $-0.626^{* * *}$ & $-0.619 * * *$ \\
\hline \multicolumn{5}{|l|}{ Marital status } \\
\hline Married (ref) & & 0 & 0 & 0 \\
\hline Separated/divorced/widowed & & $-0.695 * * *$ & $-0.856^{* * *}$ & -0.856 *** \\
\hline Single & & $-0.485^{* * * *}$ & $-0.179 * * *$ & -0.180 **** \\
\hline Number of children under 16 in $\mathrm{HH}$ & & $-0.028^{* * * *}$ & $-0.066 * * *$ & $-0.066^{* * *}$ \\
\hline \multicolumn{5}{|l|}{ Period } \\
\hline Earlier (1972-1980) (ref) & & 0 & 0 & 0 \\
\hline Middle (1981-1996) & & $-0.808^{* * * *}$ & $-1.143^{* * *}$ & $-1.117 * * *$ \\
\hline Later (1997-2005) & & $-0.267 * * *$ & $-0.686^{* * *}$ & $-0.672^{* * *}$ \\
\hline \multicolumn{5}{|l|}{ Country of birth } \\
\hline UK born (ref) & & & 0 & 0 \\
\hline \multirow{2}{*}{\multicolumn{5}{|c|}{ Age }} \\
\hline & & & & \\
\hline Age (=age/10) & & & $1.607 * * *$ & $1.609 * * * *$ \\
\hline Age squared & & & $-0.173^{* * * *}$ & $-0.173^{* * * *}$ \\
\hline \multicolumn{5}{|l|}{ Education } \\
\hline Degree+ + & & & $1.184^{* * * *}$ & $1.184^{* * * *}$ \\
\hline Professional below degree & & & $1.175^{* * *}$ & $1.176^{* * * *}$ \\
\hline A levels or equivalent & & & $0.829 * * *$ & $0.829 * * * *$ \\
\hline $\mathrm{O}$ levels or equivalent & & & 0.706 **** & $0.706^{* * * *}$ \\
\hline Primary or no qualification (ref) & & & 0 & 0 \\
\hline \multicolumn{5}{|l|}{ Interaction effects } \\
\hline White Irish in middle period & & & & 0.027 \\
\hline White Irish in later period & & & & $0.391 * *$ \\
\hline White Other in middle period & & & & -0.023 \\
\hline White Other in later period & & & & 0.023 \\
\hline Black Caribbean in middle period & & & & $-0.379 * *$ \\
\hline Black Caribbean in later period & & & & $-0.385^{* *}$ \\
\hline Black African in middle period & & & & $-1.781^{* * * *}$ \\
\hline Black African in later period & & & & $-1.512^{* * * *}$ \\
\hline Indian in middle period & & & & 0.001 \\
\hline Indian in later period & & & & 0.052 \\
\hline Pakistani/Bangladeshi in middle period & & & & $-0.901^{* * * *}$ \\
\hline Pakistani/Bangladeshi in later period & & & & $-0.735^{* * * *}$ \\
\hline Chinese in middle period & & & & -0.044 \\
\hline Chinese in later period & & & & -0.167 \\
\hline Constant & $2.438 * * *$ & $3.257 * * *$ & $-0.226^{* * *}$ & $-0.251^{* * * *}$ \\
\hline Pseudo $R^{2}$ & 0.006 & 0.026 & 0.078 & 0.078 \\
\hline$n$ & $1,060,063$ & $1,060,063$ & $1,060,063$ & $1,060,063$ \\
\hline
\end{tabular}

Note: For men aged 16-64 and resident in Great Britain. ${ }^{*} p<0.05, * * p<0.01, * * * p<0.001$

Source: Pooled data of GHS/LFS 1972-2005 


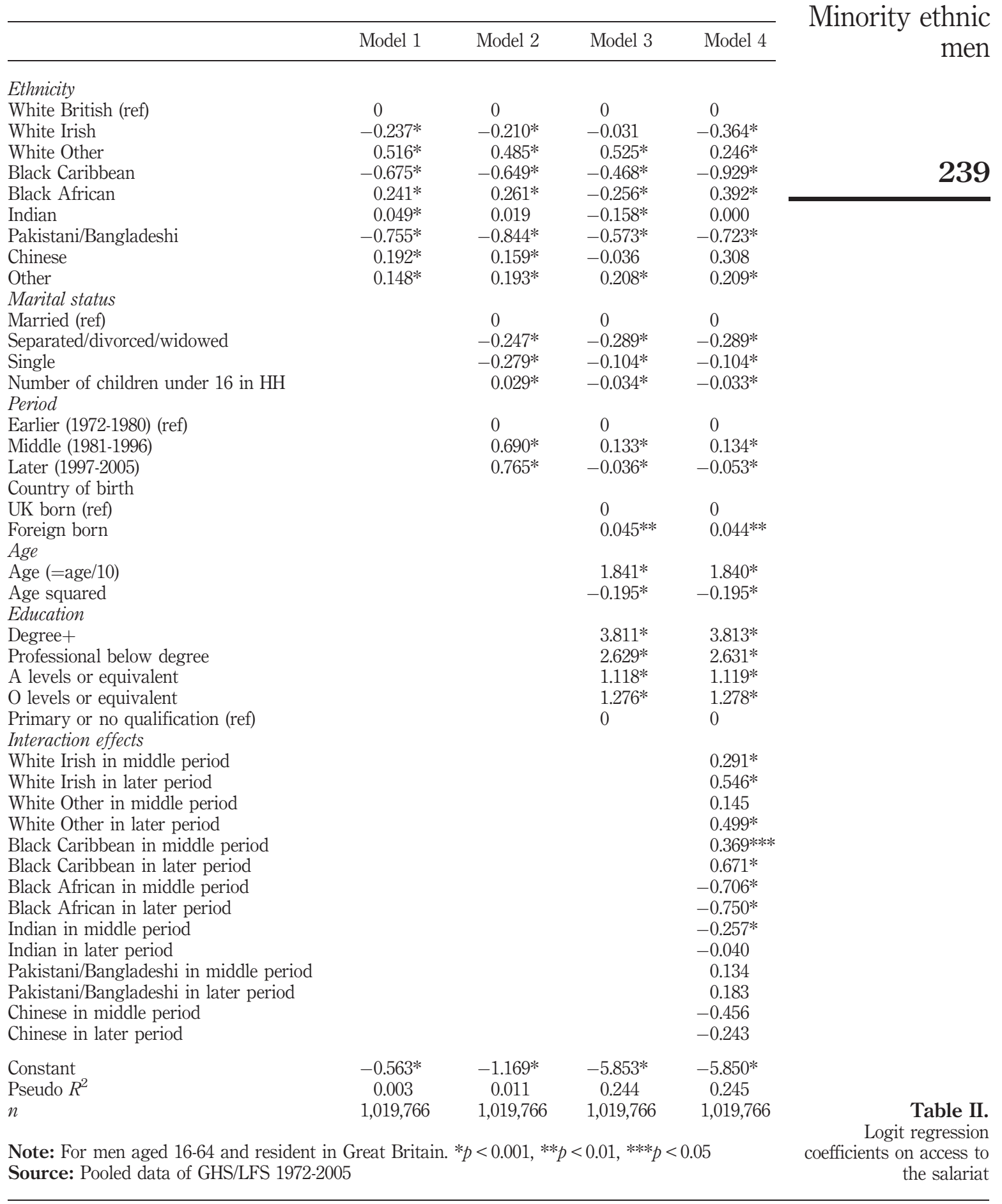


IJSSP

$28,5 / 6$

240
The data in Model 1 of Table I show that, taking the 34 years as a whole, White Other men were slightly (but not significantly) more, and men in all other ethnic groups (except the Chinese) were significantly less, likely to be in employment as compared with White British men. Judging from the magnitude of the coefficients we find that Black and Pakistani/Bangladeshi men were very much more likely to bear the brunt of unemployment. Turning to Model 2, we find that the coefficients associated with the ethnic groups were similar to those in Model 1, that non-married and men with dependent children were significantly less likely to be in employment and that the employment situation was particularly adverse in the middle period. In Model 3, the various coefficients for the respective variables were similar to those in Model 2 but additionally, we find that nativity does not make a significant difference, and that age and education have the marked effects as expected, that is, a curvilinear association between age and employment and the positive association between educational level and employment. The absence of nativity effects is at first sight rather surprising, but this has been confirmed by other research (see for example, Model and Fisher, 2002; Heath and Yu, 2004; Lindley et al., 2006).

We now turn to consider whether ethnic minorities have been narrowing the net gap over time. Controlling for all the prior variables, the interaction effects in Model 4 show that White Irish men significantly improved their employment chances as the time went on, that the White Other and Chinese men were never significantly different from the White British, that Indian men were initially disadvantaged but were no longer so in the later periods, and that on the whole, it was the Black Caribbean, Black African and Pakistani/Bangladeshi men who were not found to have made significant improvement in their employment chances. Indeed, the net position of these three groups was actually worse in the two later periods than it had been in the first period.

Turning to data on access to the salariat as shown in Table II, we find some expected patterns, such as those associated with marital status, family situation, period, age, and education. One notable difference from the previous table concerns the nativity effects. Holding constant all other variables in the models, men who were foreign-born were significantly more likely to find themselves in the salariat, although the size of this effect was rather small. This, however, does not mean that all foreign born men were equally advantaged in gaining access to the salariat. Further analysis, holding constant all other variables in Model 3, shows that foreign-born men in the White Irish and White Other groups were not significantly different from, but foreign born men in all non-White ethnic groups were significantly less likely than the White British men, to be in the salariat (data not shown but available on request).

Focusing finally on the changes over time in the net ethnic differences, as shown by the interaction effects in Model 4, we find that White Irish men were quickly catching up and were indeed outperforming their White British counterparts in the later periods; that White Other men were always outperforming their White British peers; that Black Caribbean men were making pronounced progress which formed a sharp contrast to their Black African counterparts; that men of Indian and Chinese origins were generally close to, although the former were experiencing some "penalty" in the middle period as compared with the White British; and that Pakistani/Bangladeshi men's disadvantages were somewhat, but not significantly, ameliorated in the process of time.

We thus find rather different patterns of progress over time with respect to occupational attainment and to unemployment. Most notably, Black Caribbeans were 
falling behind in terms of unemployment but catching up in access to the salariat, Black Africans were the only group whose net position deteriorated on both criteria.

\section{Discussion and conclusion}

In this paper, we have analysed the labour market situation of different ethnic groups in Britain covering a long period of 34 years from 1972 to 2005. Although numerous research findings have been reported, especially in the last ten years thanks to the release of the 1991 SARs, this is the first ever systematic and rigorous analysis in this regard as we used the best data from the government surveys and standardised all the key variables. We analysed employment status and occupational attainment both in their raw patterns and trends and in their net effects. The main findings can be summarised as follows.

In terms of overall labour market situation, we found that White British and White Other men were consistently more likely to be in employment and in the salariat. White Irish men had a success story of climbing the stratification ladder. Indian men were generally little different from the White British, confirming existing research. Chinese men were likely to engage in small-scale self-employment thus avoiding the threats of unemployment. Black Caribbean men were mainly second generation or arriving before the 1970s and, lacking the "cushion" of self-employment for whatever reasons, were most likely to face unemployment and inactivity, especially during the peak years of recession but were found to be steadily improving their access to the salariat. Black African men were most diversified: they were very highly qualified educationally and were little different from the White British men in gaining access to the salariat; on the other hand, they were most likely to face unemployment and inactivity, especially during the early 1990s. Pakistani/Bangladeshi men were found most disadvantaged in gaining access to paid work and to the salariat, with a very large proportion turning to self-employment from the early 1990s onwards, perhaps as an "escape strategy".

Turning to the relative effects, our findings, particularly those on age and education, strongly support the human capital theories and show the importance of controlling for these variables. Holding constant all the personal and socio-cultural factors, we find that White Other men generally did better than, and Indian and Chinese men were little different from, the White British men; that White Irish and Black Caribbean men were making steady progress in gaining access to the salariat; and that Black African and Pakistani/Bangladeshi men were consistently found disadvantaged in employment and in access to the salariat, with increasing net disadvantage over time.

It is of course possible that there may be additional, unmeasured, selection effects (Borjas, 1995) in accounting for the disparate patterns of change over time. For example, it might be that the Africans or Pakistanis who were in Britain in the earliest period were more "positively selected" than those who arrived later. The pioneers might well be more highly motivated and determined than their successors treading more familiar routes. In the case of our other groups - Indians, Irish, Caribbeans and Chinese - they had arrived rather earlier and so we would not observe any "pioneer effect" in their case during our period. It is also possible that there have been changing patterns of migration from Africa over this period, in particular with greater number of refugees coming from countries such as Somalia in the later period.

While unmeasured selection effects may well explain the relative deterioration of the Pakistani and Black African position over time, it is less obvious how they can account for the growing polarization over time within the Black Caribbean community. As we saw, Black Caribbeans were disadvantaged both with respect to unemployment
Minority ethnic men 
IJSSP

$28,5 / 6$

242 and with respect to access to the salariat in the early part of our period. By the later part of the period, their (net) situation with respect to unemployment had become even worse while their (net) situation with respect to the salariat had markedly improved, removing much of their earlier disadvantage. Why does this pattern apply to the Black Caribbeans and not to the other groups?

One important feature of the group of Black Caribbean ancestry is that it is one of the groups that has become socially most integrated with the majority population, as measured for example by levels of intermarriage (which reach up to 50 per cent among the second generation). In this way it is quite different from the Indian or Pakistani groups (and even to some extent from the Chinese, whose high intermarriage rates are specific to the highly educated). This suggests that we may be seeing a version of "segmented assimilation", although not in the sense proposed by Portes and Zhou (1993). In the Black Caribbean case we may be seeing segmented assimilation within a community whereas Portes and Zhou referred to segmented assimilation between communities. Thus for some Black Caribbeans we may be seeing assimilation into the white working class (although we would prefer to find a different term than assimilation since Caribbeans may well be transforming working-class white culture rather than simply assimilating to it). In contrast for other Black Caribbeans we may be seeing upward assimilation into the white middle class. What we may be seeing then is the effect of social capital, a variable which unfortunately is not available in our pooled dataset. This pattern of segmented assimilation is unlikely to be happening to the same extent with the Indian or Pakistani groups which have much lower rates of intermarriage and much higher rates of community closure.

All this shows that any simple, binary, account of ethnic relations is likely to be misleading. The White British do enjoy advantages in terms of employment but for class positions, there are more differences among the minority ethnic groups than between them and the White group. On the other hand, whilst some ethnic penalties are indeed found, we also found some encouraging signs, such as amongst the White Irish, Indian and even Black Caribbean groups. More concerted efforts are needed to help Black African and, inter alia, Pakistani/Bangladeshi groups to improve their labour market situations.

\section{Notes}

1. We are grateful to the ESRC for funding this research (Socio-economic position and political support of the BMEs in Britain (1971-2004), ESRC (RES-163-25-0003)) and for the UK Data Archive for making data accessible to us.

2. The LFS is available from 1973 onwards, but there is insufficient information on minority ethnic groups prior to 1983.

3. The sample size for the Chinese group is too small before 1983 .

4. This finding is confirmed by using the Home Office Citizenship Survey (2005), which shows that as against an overall rate of 78.8 per cent in employment in England and Wales for men aged 16-64, that for the Chinese was only 55.9 per cent, the lowest of all groups.

\section{References}

Berthoud, R. and Blekesaune, M. (2006), "Persistent employment disadvantage, 1974 to 2003", working paper 2006-09 (PDF), Institute for Social and Economic Research, University of Essex, Colchester. 
Borjas, G. (1995), "Ethnicity, neighbourhoods and human capital externalities", American Economic Review, Vol. 85, pp. 365-90.

Brook, K. (2005), "Labour market participation: the influence of social capital", available at: www.statistics.gov.uk/articles/labour_market_trends/lm_social_capital.pdf

Carmichael, F. and Woods, R. (2000), "Ethnic penalties in unemployment and occupational attainment: evidence for Britain”, International Review of Applied Economics, Vol. 14 No. 1, pp. 71-98.

Clark, K. and Drinkwater, S. (1998), "Ethnicity and self-employment in Britain”, Oxford Bulletin of Economics and Statistics, Vol. 60, pp. 383-407.

Dale, A., Fieldhouse, E. and Holdsworth, C. (2000), Analysing Census Microdata, Arnold, London.

Daniel, W.W. (1968), Racial Discrimination in England, Penguin, London.

Drew, D., Gray, J. and Sporton, D. (1997), "Ethnic differences in the educational participation of 1619 year-olds", in Karn, V. (Ed.), Ethnicity in the 1991 Census, Vol. 4, The Stationery Office, London, pp. 17-28.

Hamberger, J. and Hewstone, M. (1997), "Inter-ethnic contact as a predictor of blatant and subtle prejudice: tests of a model in four west European nations", British Journal of Social Psychology, Vol. 36, pp. 173-90.

Heath, A. and Cheung, S.Y. (2007), "Minority ethnic disadvantage in the labour market: Britain", in Heath, A. and Cheung, S. (Eds), Ethnic Differences across Countries, OUP, Oxford.

Heath, A. and Li, Y. (2007), "Measuring the size of the employer contribution to the ethnic minority employment gap", consultation paper for National Employment Panel, London.

Heath, A.F. and Yu, S. (2004), "The puzzle of minority ethnic disadvantage", in Heath, A.F., Ermisch, J. and Gallie, D. (Eds), Understanding Social Change, Proceedings of the British Academy, Oxford University Press, Oxford, pp. 187-234.

Iganski, P. and Payne, G. (1999), "Socio-economic re-structuring and employment: the case of minority ethnic groups", British Journal of Sociology, Vol. 50 No. 2, pp. 195-216.

Karn, V. (Ed.) (1997), Ethnicity in the 1991 Census, Vol. 4, The Stationery Office, London.

Li, Y. (2004), "Samples of anonymised records (SARs) from the UK censuses: a unique source for social science research", Sociology, Vol. 38 No. 3, pp. 553-72.

Li, Y. (2005), "Social capital, ethnicity and the labour market", available at: http:// engagingcommunities2005.org/abstracts/Li-Yaojun-final.pdf

Li, Y. (2006a), "Social capital, social exclusion and wellbeing”, in Scriven, A. and Garman, S. (Eds), Public Health: Social Context and Action, Sage, London.

Li, Y. (2006b), "Assessing information needs and gaps for researching minority ethnic entrepreneurship in Britain”, consultation paper for the ESRC/DTI/CRE/EMDA, Swindon.

Lindley, J., Dale, A. and Dex, S. (2006), "Ethnic differences in women's employment: the changing role of qualifications", Oxford Economic Papers, Vol. 58, pp. 351-78.

Model, S. and Fisher, G. (2002), "Unions between blacks and whites: England and the US compared", Ethnic and Racial Studies, Vol. 25, pp. 728-54.

Portes, A. and Zhou, M. (1993), "The new second generation: segmented assimilation and its variants among post-1965 immigrant youth", Annals of the American Academy of Political and Social Science, Vol. 530, pp. 74-96.

\section{Further reading}

Li, Y. and O'Leary, R. (2007), "Progress in reducing Catholic disadvantages in Northern Ireland", in Heath, A. and Cheung, S. (Eds), Ethnic Differences across Countries, OUP, Oxford.

\section{Minority ethnic}

men 
IJSSP

$28,5 / 6$

244

\begin{abstract}
About the authors
Yaojun Li is Professor of Sociology at Manchester University, UK. His research interests are in social mobility, social capital, political participation, educational and occupational attainment, labour market situation of minority ethnic groups, and cross-national comparisons. Recent publications have appeared in European Sociological Review, British Journal of Sociology, British Journal of Political Sciences, Sociology, Work, Employment and Society, Sociological Review, and Sociological Research Online. He also has several book chapters. Yaojun Li is the corresponding author and can be contacted at:Yaojun.Li@Manchester.ac.uk

Anthony Heath is Professor of Sociology and Head of Department at the University of Oxford, UK. His research interests cover several major areas in sociological inquiry, such as class analysis, political affiliation, educational attainment, ethnicity and cross-national comparisons. He has written over ten books and nearly two hundred papers which have appeared in major Sociology journals in the USA and Europe. He is also an FBA and Official Fellow at Nuffield College, Oxford University.
\end{abstract}

To purchase reprints of this article please e-mail: reprints@emeraldinsight.com Or visit our web site for further details: www.emeraldinsight.com/reprints 